\title{
Rheological Studies of Microfibrillar Cellulose Water Dispersions
}

\author{
Marco Iotti • Øyvind Weiby Gregersen • \\ Størker Moe $\cdot$ Marianne Lenes
}

Published online: 28 September 2010

(C) The Author(s) 2010. This article is published with open access at Springerlink.com

\begin{abstract}
The rheological behaviour of microfibrillar cellulose (MFC) water dispersions has been investigated. For the first time a detailed study of shear dependent viscosity at low and high shear rate is presented. A peculiar time dependent behaviour measured in the area between 0 and $1000 \mathrm{~s}^{-1}$ was identified. The study shows a hysteresis loop in the shear rate-viscosity relationship at low shear rate. Additional time dependent shear rate measurements were performed, and a hypothesis for a mechanism of interaction and formation of a fibrils network was suggested. Higher temperature caused lower viscosity values, and this difference was increased at higher shear rate values. Oscillatory measurements showed how the closeness of the fibrils helps network creations. Data obtained from high shear measurements showed that $1 \%$ MFC water dispersions had a dilatant behaviour at ultra high shear rates with values increasing from 120 to $300 \mathrm{~Pa} \mathrm{~s}$ in the area between 180,000 and $330,000 \mathrm{~s}^{-1}$.
\end{abstract}

Keywords Microfibrillar cellulose $\cdot$ Rheology $\cdot$ Coating · Packaging

\section{Introduction}

Cellulose is a structural polymer that provides mechanical properties to higher plant cell, and the role of cellulose is

M. Iotti $(\bowtie) \cdot \varnothing$. W. Gregersen · S. Moe Department of Chemical Engineering, NTNU, Sem Sælandsvei 4, 7491 Trondheim, Norway e-mail: marco.iotti@pfi.no

M. Lenes

Paper and Fibre Research institute, PFI, Høgskoleringen 6B, 7491 Trondheim, Norway primarily to give the plant sufficient strength. An important building block for natural fibre strength and stiffness is the cellulose microfibril [1]. The fibre cell wall is essentially a composite material consisting of a framework of cellulose microfibrils embedded in a matrix of mostly hemicelluloses and lignin [2]. The cellulose chains are organized into strands of cellulose microfibrils [3]. This organization gives the microfibrils mechanical strength properties that are close to the theoretical limit for cellulose [4].

The production and characterization of microfibrillar cellulose (MFC) from wood fibres has been described by Turbak et al. [5] and Herrick et al. [6]. MFC was obtained by disintegrating cellulose fibers at high shear. This procedure resulted in the production of a highly entangled network consisting of nanoscale size elements with a gellike behaviour for water dispersions at $1 \%$ or lower concentrations of MFC [5-7].

Because of the unique characteristics of MFC particles, such as; a very high specific surface area [8], and the formation of a highly porous network [9], an extensive amount of research has been done in the last 30 years. Several recent publications demonstrate how MFC can be used for various purposes within material technology, such as; reinforcement in nanocomposites $[4,7,10,11]$ dispersion stabilizers [12-15], antimicrobial films [16], filtration media [17] and oxygen barrier material in food and pharmaceutical applications [18].

This last characteristic is of particular interest because it could solve a weakness traditionally connected with paper based packaging, and open a new way for packaging totally derived from renewable sources.

Paper and paperboard are the only renewable materials widely used for food packaging applications [19]. However their application is limited by poor barrier properties and their high sensitivity to moisture. These are among the 
main reasons for the success of synthetic plastic packaging materials, whose impact on the environment is under debate. In order to solve problems related to the disposal of food packaging after use, major efforts are under way to identify alternative materials derived from agricultural crops [20, 21]. MFC is a possible solution to create gas barrier. Recent discoveries in energetic performances [22, 23 ], together with the cost reductions in the production process, make MFC a good candidate.

MFC can be applied as a coating on paper and paperboards due to its gel-like behaviour, its chemical compatibility with the substrates and the ability to disperse it in water. The coating applications compared with a laminated system have the advantages of high flexibility, absence of adhesive and a low production cost.

However, even if the rheological characteristics of MFC suspensions are fundamental to understand possible utilizations in material and food industries (e.g. in coating applications, as thickening agent, in extrusion processes), little has been published. Herrick et al. [6], who first studied the rheological behaviour of MFC, discovered a pseudoplastic (shear thinning) behaviour for a $2 \%$ water dispersion characterized by a viscosity of 17,400, 264 and $136 \mathrm{mPa} \mathrm{s}$ at 10,1000 and $5000 \mathrm{~s}^{-1}$, respectively. Lowys et al. [24] investigated for the first time the storage and loss modulus and values for $1 \% \mathrm{w} / \mathrm{w}$ MFC water dispersion, and their findings were later confirmed by Pääkkö et al. [22].

The few published studies do not consider time dependency, the origin of the pulp and high shear rate rheology, while other parameters as temperature and concentration dependencies are just briefly addressed as a corollary of other studies. The temperature dependence of a $2 \%$ MFC water dispersion was investigated by Herrick et al. [6] in the 1980 s at a fixed shear rate of $1000 \mathrm{~s}^{-1}$. Since then no one has measured a wider area of viscosity with modern instruments. Concentration studies were performed by Lowys et al. [24] and Pääkkö et al. [22]; the data of Lowys were only at the fixed shear rate of $10 \mathrm{~s}^{-1}$. Moreover, the shear viscosities as function of shear rate curves are not commented in the second paper.

In conclusion, the rheological data presented in literature so far, are insufficient to formulate a proper explanation of the peculiar behaviour of MFC dispersion and its high gel forming properties.

In order to get a deeper understanding of MFC rheology this study aims to provide an in-depth investigation of the rheological behaviour of microfibrillar cellulose (MFC) water dispersions in shear rate ranges of industrial interest.

MFC water dispersions were studied at various concentrations (1-4\%) and at temperatures between 25 and $60{ }^{\circ} \mathrm{C}$ to complement data previously reported in literature.
The studies also investigated the influence of the pulp type on the MFC rheology by selecting two different types of commercial pulp qualities.

In addition to shear dependent viscosity measurement, series of oscillatory test were done to make the study as accurate as possible.

\section{Materials and Methods}

\section{Raw Material}

Two different types of cellulose were selected to produce microfibrillated cellulose: (I) ECF (elemental chlorine free) fully bleached sulphate pulp mainly based on juvenile Picea abies and (II) ECF (elemental chlorine free) fully bleached sulphate cellulose mainly based on mature Pinea abies with up to $5 \% \mathrm{w} / \mathrm{w}$ pine (Pinus sylvestris). To avoid plugging of the homogenizing equipment, fibres were cut to reduce the fibre length. Cutting the fibres into shorter lengths is also believed to increase the rate of homogenization by exposing increased fibre cross-sectional area to fibrillation [6]. The pulp was dispersed in water and thick sheets were made out of that. The wet pulp sheets were then cut by repeated shredding in an ordinary office shredder, which resulted in an average fibre length of approximately $1 \mathrm{~mm}$. The resulting pulp was diluted to $1 \%$ consistency and subjected to ten passes through a Gaulin M12 homogenizer, with a pressure drop of 600 bar at each pass as previously described [5]. The obtained MFC is described in a previous work [18].

\section{Concentration of MFC}

From the $1 \%$ water dispersion of MFC, the other MFC concentrations $(2 \%, 3 \%$ and $4 \%$, respectively) were obtained by centrifugation in a Heraeus 400R (Thermo Fisher Scientific Inc., Waltham, MA, USA) with time and temperature as described in Table 1.

\section{Rheological Measurements}

The low shear and oscillatory rheological properties of MFC dispersions were measured on a Physica MCR-301 (Anton Paar GmbH, Graz, Austria) rotational rheometer, using the RheoPlus software. The high shear rate measurements were performed using an ACAV A2 capillary rheometer (ACA systems, Oy, Finland). Shear rate/time dependent tests at low shear rates were also performed with a Physica MCR-301 (Anton Paar GmbH, Graz, Austria) in a separate laboratory (Kosnäs $\mathrm{AB}$, Frövi, Sweden) to confirm the obtained rheogram. 
Table 1 Description and characterization of samples under study

\begin{tabular}{llllllll}
\hline $\begin{array}{llllll}\text { Sample } \\
\text { code }\end{array}$ & $\begin{array}{l}\text { Pulp } \\
\text { type }\end{array}$ & $\begin{array}{l}\text { MFC } \\
\text { conc. (\%) }\end{array}$ & $\begin{array}{l}\text { Geometry } \\
\text { (parallel plates } \\
\text { diameter, mm) }\end{array}$ & & \multicolumn{2}{l}{ Concentration process data } & Laboratory \\
\hline A & I & 1 & 50 & T (Celsius) & t (min) & \\
B & II & 1 & 50 & - & - & - & NTNU \\
C & I & 2 & 50 & - & - & - & NTNU \\
D & I & 3 & 50 & 2500 & 25 & 60 & NTNU \\
E & I & 4 & 50 & 3000 & 25 & 60 & NTNU \\
F & I & 1 & 50 & -300 & 28 & 60 & NTNU \\
G & I & 1 & 75 & - & - & - & Control \\
\hline
\end{tabular}

Shear Rate/Time Dependency: Low Shear Controlled Mode Tests

The Physica MCR-301 was used in controlled shear mode to test the shear rate/time dependency of $1 \%, 2 \%, 3 \%$ and $4 \%$ MFC dispersions. The rheometer was equipped with a temperature controlled lower plate (ERD, PPTD200/62/ TG) to regulate temperatures between 25 and $60{ }^{\circ} \mathrm{C}$. A parallel plate geometry type was selected as the most appropriate for the measurements. Two plate sizes were used: $75 \mathrm{~mm}$ diameter (concentricity $\pm 8 \mu \mathrm{m}$ and parallelity $\pm 7 \mu \mathrm{m}$ ) and $50 \mathrm{~mm}$ diameters (concentricity $\pm 5 \mu \mathrm{m}$ and parallelity $\pm 2 \mu \mathrm{m}$ ). For both geometries the base plate was roughened to prevent wall slip. The $50 \mathrm{~mm}$ diameter was the used one for the analysis unless other information is given. The gap was $1 \mathrm{~mm}$ and the sample was allowed to rest $10 \mathrm{~min}$ before starting the preshearing. To prevent sample drying, specific covers and distilled water on the geometries were used. Specific covers around samples and distilled water on the geometries were used to prevent sample drying due to the long running time and/or the high temperature selected.

The rheometer at the control lab was equipped with a roughened temperature controlled lower plate (P-PTD200) and measurements were performed plate/plate using a $50 \mathrm{~mm}$ size smooth geometry (concentricity $\pm 5 \mu \mathrm{m}$ and parallelity $\pm 2 \mu \mathrm{m})$.

The shear rates investigated for all equipments were between 0 and $1000 \mathrm{~s}^{-1}$. Acceleration, deceleration, ratios and pause into the measurements are presented in Table 2. All measurements were performed at $25^{\circ} \mathrm{C}$ unless otherwise indicated.
Shear Rate/Time Dependency: High Shear Controlled Mode Tests

High shear rate measurements were performed on a $1 \%$ MFC water dispersion. The measurements were done with a $2 \mathrm{~mm}$ (dia.) $90 \mathrm{~mm}$ (length) capillary. Because MFC samples usually contain some large particles due to the production process it wasn't possible to test the sample with a $0.50 \mathrm{~mm}$ capillary. The resulting measurements were in the range between 180,000 and $330,000 \mathrm{~s}^{-1}$. Measurements were conducted at $25{ }^{\circ} \mathrm{C}$.

\section{Oscillatory Measurements}

Oscillatory measurements were performed on $1 \%, 2 \%$ and $3 \%$ MFC. A roughened $50 \mathrm{~mm}$ plate was used for the sample as it was considered the best solution in our range of concentration. The gap was $1 \mathrm{~mm}$ and the sample was allowed to rest $10 \mathrm{~min}$ before starting the pre-shearing. Specific covers around samples and distilled water on the geometries were used to prevent sample drying due to the long running time and/or the high temperature selected.

Before the dynamic viscoelastic measurements, the linear viscoelastic region was determined by torque sweeps for all dispersions. The torque sweeps were measured for a strain percentage between 0.01 and $100 \%$ at the frequency of $0,1 \mathrm{~Hz}$.

Frequency sweep measurements (torque sweep measurements), were measured with a rotation of $50 \mathrm{~s}^{-1}$ in the linear viscoelasticity region. The frequency sweeps were carried out in the range of $0.01-100 \%$ in the linear viscoelastic region, controlling the strain.

Table 2 Scheme of the rotational rheometer analysis for low shear measurements

\begin{tabular}{llllllllll}
\hline Step & 1 & 2 & 3 & 4 & 5 & 6 & 7 & 8 & 9 \\
\hline Shear rate $\left(\mathrm{s}^{-1}\right)$ & 50 & 0 & $0.1-1000$ & $1000-0.1$ & 0 & $0.1-1000$ & $1000-0.1$ & 0 & $0.1-1000$ \\
Time $(\mathrm{s})$ & 120 & 600 & 300 & 300 & 120 & 300 & 300 & $1000-0.1$ \\
\hline
\end{tabular}


Additional Rheological Tests to Study the MFC Time Dependent Rheological Behaviour

Time-dependent behaviour and shear-dependent behaviour of non-Newtonian liquids are easily confused. Since standard measurements of shear-dependent behaviour also must yield a time-dependent response, time-dependent phenomena like thixotropy or rheopexy may be masked by shear-dependent behaviour. Thus, if one should suspect time-dependent behaviour, care must be taken to introduce experiments which study time-dependent behaviour at a given shear rate or strain. Only if the constant shear rate measurements show no time-dependent behaviour, the curve can be red trough a pure shear-dependent nonNewtonian model.

To determine if there is a time dependency in our viscosity profile results additional tests at constant shear were conducted.

Time dependent studies at shear rates of $5,10,20 \mathrm{~s}^{-1}$ were conducted in the incremental curve and at $10 \mathrm{~s}^{-1}$ in the decrement curve. At these values, the shear rate was held constant for $5 \mathrm{~min}$ and the viscosity development was monitored.

\section{Results and Discussion}

\section{MFC Nature}

Today, Nanofibrillar cellulose from the same cellulose source can be obtained with different combination of pretreatments and treatments. This makes it obtainable from several sources and the discussion about what can and cannot be called MFC is ongoing. Our experiment uses the same manufacturing procedure described by Turbak and Herrick [5, 6] with additional mechanical pre-treatment already reported in literature by Syverud [18]. Since Turbak and Herrick are the ones who discovered MFC, we are sure of dealing with MFC water dispersions.

\section{Shear Controlled Mode Test: Low and High Shear Rate Tests}

The flow experiments of MFC resulted in a peculiar behaviour of the dispersion that is apparent for all samples studied. Figure 1 shows a typical curve for a $1 \%$ water dispersion of MFC in the shear rate range between 0 and $1000 \mathrm{~s}^{-1}$. The curve is the average of 3 different measurements of sample A (Table 1), ran according to the scheme in Table 2.

It is possible to identify certain characteristics common for all measurements: (1) a yield stress, (2) a shear thinning behaviour and (3) a hysteresis loop in the area between 0

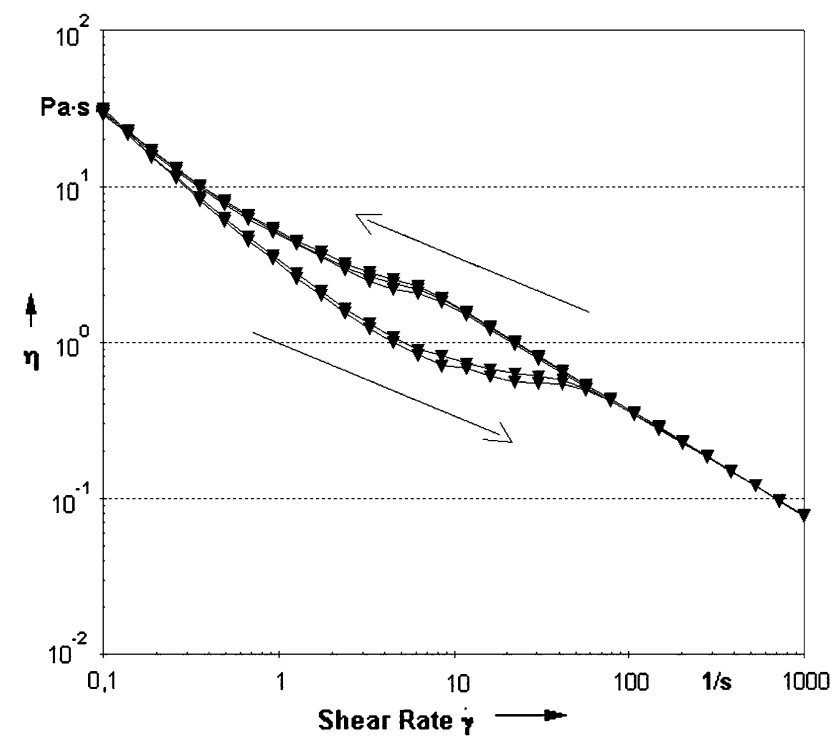

Fig. 1 Shear controlled mode test: Resulting average curve of 3 rheological measurements of sample A $\left(0-1000 \mathrm{~s}^{-1}\right)$ at $25^{\circ} \mathrm{C}$. It is possible to identify the 3 runs for the increasing share rate curve $\left(0-1000 \mathrm{~s}^{-1}\right)$ and the 3 runs for the decreasing share rate curve $\left(1000-0 s^{-1}\right)$ and notice the difference between them

and $50 \mathrm{~s}^{-1}$. Even if the first two characteristics are already reported in literature $[6,24]$, the hysteresis loop has not been previously described. Its study can help in the understanding of the highly gel-like behaviour of MFC. Moreover, it is possible to already identify a yield stress at a concentration of $1 \%$. This measurement differs from the data of Lowys et al. [24], who found a yield stress only at concentrations above 3\%. This last observation shows that our MFC dispersions show a network formation tendency already at $1 \%$. Even at $1000 \mathrm{~s}^{-1}$ the dispersion is still shear thinning, no Newtonian/linear behaviour is observed.

Figure 2 shows and compares 4 different curves representing different samples described in Table 1: inverted filled triangle sample $\mathrm{A}$, open circle sample $\mathrm{B}$, open square sample F, open diamond and sample G. No significant differences were identified among the curves. The fact that every curve represents an average of 3 different runs, each consisting of 3 up and down curves confirms that there are no significant differences between the samples. It is also possible to show that the two different types of pulp (Sample A and B) do not show significant differences in rheological terms.

Figure 3 shows viscosity plotted against shear rate for MFC dispersions of different concentrations (1\%, $2 \%, 3 \%$, $4 \%)$. Higher concentrations results in increased yield stress and higher viscosities along the entire curve. Higher concentrations of fibrils facilitate the creation of a network and structure, by the creation of bonds between fibrils. The development of a structure causes, unsurprisingly, an increase in viscosity. 


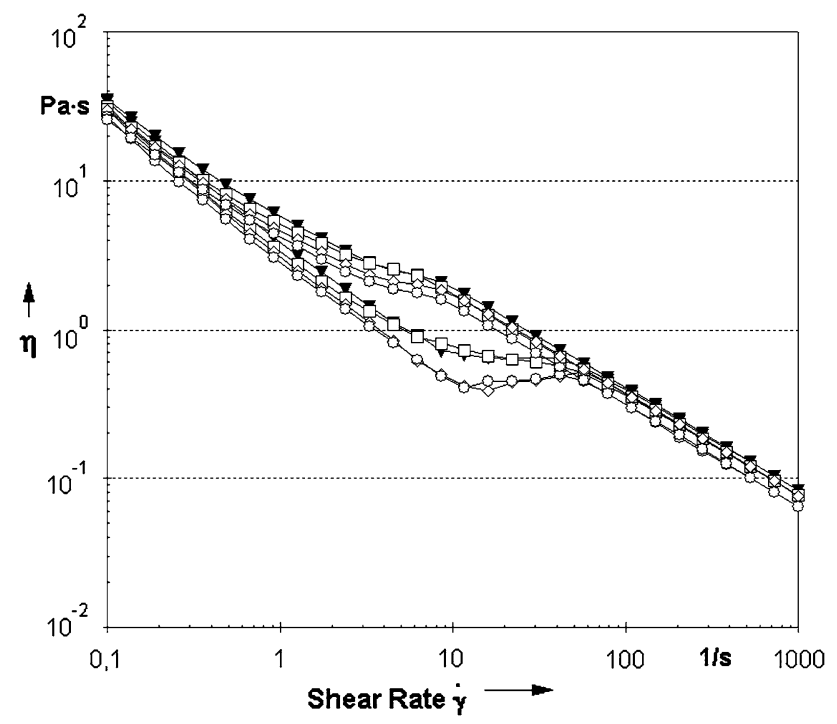

Fig. 2 Shear controlled mode test: Rheological comparison of different samples at $25{ }^{\circ} \mathrm{C}$ : inverted filled triangle samples A (1\%), open circle sample B (1\%), open square sample F (1\%), open diamond sample $\mathrm{G}(1 \%)$

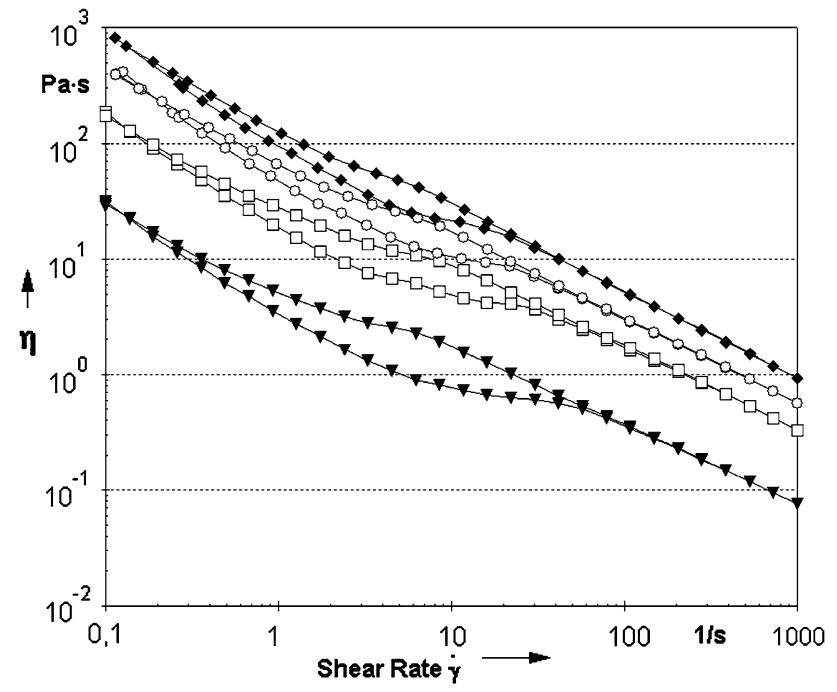

Fig. 3 Shear controlled mode test: rheological comparison of pulp type I at different concentrations at $25{ }^{\circ} \mathrm{C}$ : inverted filled triangle samples A $(1 \%)$, open square sample C (2\%), open circle sample D (3\%) filled diamond sample E (4\%)

Temperature dependency is taken into consideration in Fig. 4. Sample A measurements are reported at 25, 40 and $60{ }^{\circ} \mathrm{C}$. There is a clear reduction of viscosity with increasing temperature. This is possibly due to the combination of two different effects. Part of it is surely due to the well known reduction in viscosity of water as the temperature increase. An additional decrease may be due to the deswelling of the fibres which increase the fibres' and fibrils' mobility. The mechanism involved is most probably the same already known for cellulose fibres [25]; heat

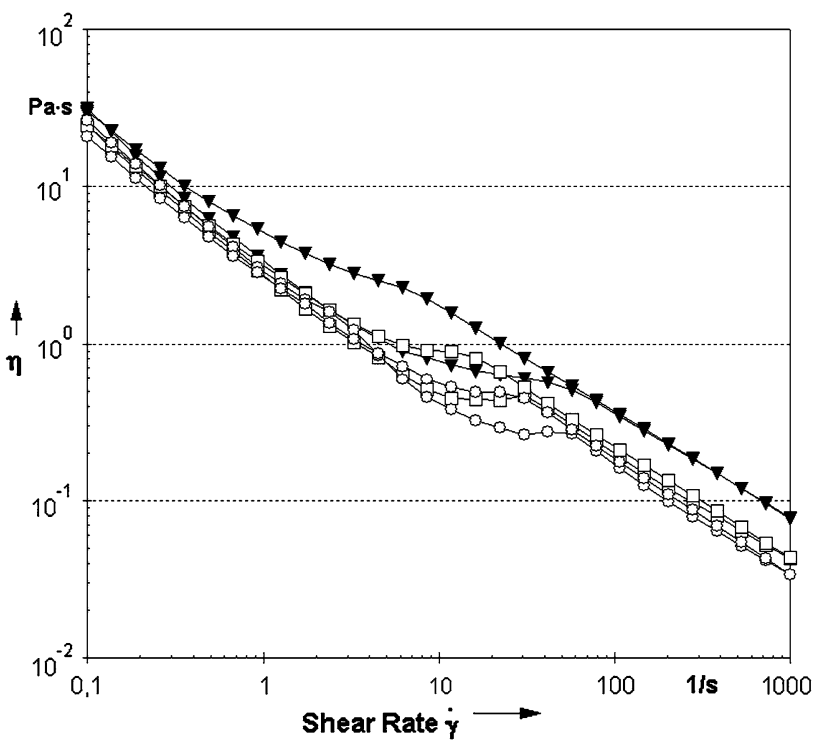

Fig. 4 Shear controlled mode test: Rheological comparison of pulp type I at different temperatures: inverted filled triangle samples A at $25^{\circ} \mathrm{C}$, open square sample A at $40{ }^{\circ} \mathrm{C}$, open circle sample A at $60{ }^{\circ} \mathrm{C}$

treatments reduce the ability of a fibre to take up water [26]. The ability of cellulose and hemicelluloses to take up water and swell is an exothermic reaction. The fibres are fully saturated with water during treatment in a hot disperser or refiner. The maximum possible moisture content measured as WRV (water retention value) or fibre saturation point and the corresponding swelling of fibers decrease with increasing temperature. In other words, fibres deswell with increased temperature.

Moreover the higher temperature introduces energy able to break down structures previously formed, allowing freedom of movement to the fibrils and a consequent reduction of viscosity.

As shown in Fig. 5, high shear rate measurement of $1 \%$ MFC (sample A) exhibits dilatant behaviour. This kind of behaviour is usual for pigments with a narrow particle size distribution [27]. This behaviour is not positive for traditional paper coating machineries which work in this range of shear rates (air knife, roll coater, rod coater, blade coater), and a shear thinning behaviour is required. Viscosities higher than $100 \mathrm{~Pa} \mathrm{~s}$ are also not very suitable for coating applications, and in this state the $1 \%$ MFC water dispersion can't be used for high shear coating applications.

\section{Oscillatory Measurements}

Storage $\left(G^{\prime}\right)$ and loss $\left(G^{\prime \prime}\right)$ moduli were measured for MFC dispersions at 1,2 and 3\% concentrations. Figure 6 shows the resulting curves obtained after 3 measurements of every concentration. As expected, both the loss modulus and the 
Fig. 5 Shear controlled mode test at high shear rate for sample A at $25{ }^{\circ} \mathrm{C}$. The three symbols inverted filled triangle, filled circle and filled square represent three different run of samples A

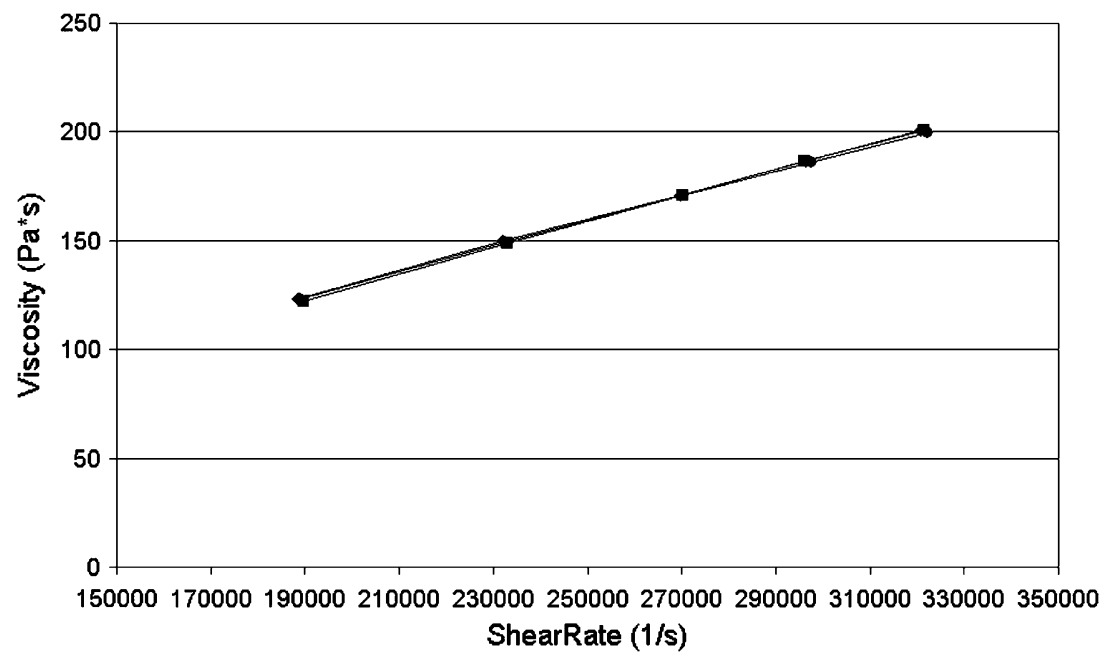

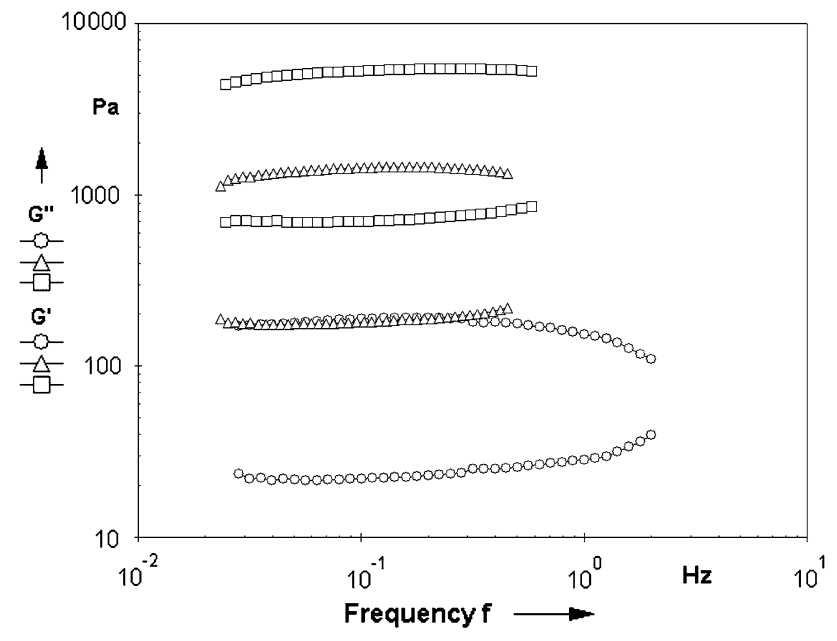

Fig. 6 Oscillatory measurements: Storage $\left(G^{\prime}\right)$ and Loss modulus $\left(G^{\prime \prime}\right)$ results at $25^{\circ} \mathrm{C}$ for samples at different concentrations: open circle sample A (1\%) open triangle samples C (2\%), open square sample D (3\%)

storage modulus increase with increasing concentration, confirming the general trend shown in Fig. 3. These results confirm the viscoelastic character of the dispersions already reported in literature $[6,22]$. The differences between $G^{\prime \prime}$ and $G^{\prime}$ are quite similar in absolute terms the different concentrations. They both increase by an order of magnitude for each concentration increase. This is in agreement with the general trend already evidenced in the shear controlled mode tests.

Study of the MFC Behaviour and Its Network Forming Characteristics

The shear rate-viscosity hysteresis of MFC dispersions identified here is substantial for the understanding of the solid-like behaviour and gel structure of MFC suspensions.

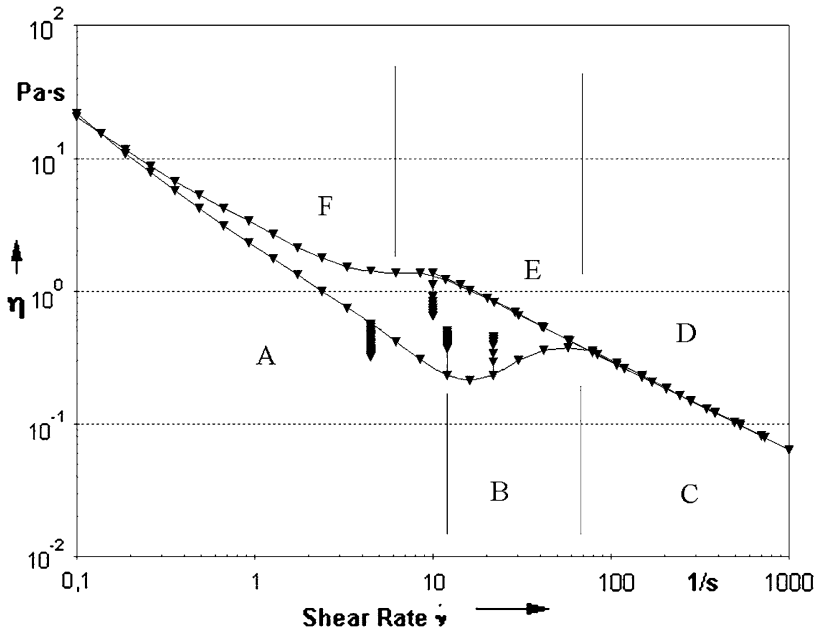

Fig. 7 Typical shear rate-viscosity curve for sample A at $25^{\circ} \mathrm{C}$ and additional shear controlled test results added at 5, 10 and $20 \mathrm{~s}^{-1}$ in the increasing shear rate curve $\left(0-1000 \mathrm{~s}^{-1}\right)$ and at $10 \mathrm{~s}^{-1}$ in the decreasing shear rate curve $\left(1000-0 \mathrm{~s}^{-1}\right)$

Suspecting a time-dependent behaviour from the hysteresis, experiments which study time dependency at given shear rate were undertaken. These tests were conducted focusing on the shear rate range where the hysteresis loop is apparent (between 0 and $50 \mathrm{~s}^{-1}$ ).

Figure 7 shows an example of a typical shear rate-viscosity curve for $1 \%$ water dispersion of MFC. Moreover, additional shear controlled mode test results are added to the curve and discussed. It is possible to identify the 4 different points for further investigation between 5 and $20 \mathrm{~s}^{-1}$. To discuss the MFC behaviour, the curve was divided in 6 different areas. A, B and $\mathrm{C}$ for the curve from 0 to $1000 \mathrm{~s}^{-1}$ and $\mathrm{D}, \mathrm{E}$ and $\mathrm{F}$ to characterize the back curve that goes from 1000 to $0 \mathrm{~s}^{-1}$.

The analysis of this curve allowed us to postulate 3 different network structures in the area of the measurements: 
(1) A no-shear structure, "yield stress"

(2) A high shear structure, "high viscosity"

(3) A low shear structure, "low viscosity"

\section{Area A}

The curve starts with a yield stress and a no-shear structure is present. The shear causes a slow breakdown of the no-shear structure and, as the shear rate increases, shear thinning is the dominating effect. Under shear, fibrils and nanofibrils orient along flow lines analogous to the behaviour of high polymers, causing a decrease of viscosity. This phenomenon is common for dispersions, and e.g. found in traditional paper coating suspensions [27, 28]. Holding the shear constant at $5 \mathrm{~s}^{-1}$ for $5 \mathrm{~min}$, shows a further decrease of viscosity until an equilibrium value. This result is in agreement with a thixotropic time dependent behaviour.

\section{Area B}

In this area the formation of a shear induced structure is hypothesized; the viscosity stops decreasing and actually starts increasing until a maximum at approximately $80 \mathrm{~s}^{-1}$.

We suggest that a shear induced structure is formed and that this is possible because of the peculiar and unique characteristics of MFC water dispersions.

The MFC consists of long thin particles with a very high specific surface area covered by hydroxyl groups that can take part in formation of temporary hydrogen bonds and Van der Waals interactions (the same that are holding together crystalline and amorphous cellulose) between the particles. The fact that the structure is recognizable only at a certain shear rate may be due to the organization of the nanofibrils in the shear field. This concentration allows the MFCs to be close enough to organize themselves into structure and influence an increase of viscosity. It is not difficult to believe in this hypothesis if the nature of cellulose, the centrifuge forces effect and the relation between viscosity and concentration are kept in mind.

In this specific area (B) the structure is not fully formed and the fibrils are still disoriented. The network formation is supposed to be the reason why the system shows a dilatant-type viscosity increase.

Supporting the hypothesis of such network creation is the increase of viscosity once the shear is held constant at values of $10 \mathrm{~s}^{-1}$ and $20 \mathrm{~s}^{-1}$. Instead of the decrease seen at $5 \mathrm{~s}^{-1}$, we have the opposite phenomena which again suggests a shear and time dependent formation of a structure. The rheopectic system behaviour is partially masked by the shear dependent, shear thinning behaviour. However in time dependent terms, this area of the curve has rheopectic behaviour.
Area $C$

We suggest that from this point the high shear structure is finally formed and that a pure shear-thinning behaviour is observed. The final equilibrium (in the shear) is present because an oriented structure is formed; the consequent decrease in viscosity is due to the stability of the structure and the orientation that allow less disturbance of the flow. The shear thinning behaviour is again dominating, and the viscosity decreases with shear rate. However, even if the curve is linear, the viscosity is higher than a hypotetical projection of a classic shear thinning behaviour. We believe that this is an additional support of the hypothesized structure.

In literature, the shear thickening behaviour of clay or starch granulate suspensions have been explained by particle "structuring" induced by shearing [29-31]. The model we suggested in this work to discuss and analyze the data obtained from the measurements is consistent with the general dilatant behaviour of other particle suspensions. However, in our case due to the nature of the dispersion, this dilatant behaviour is overlaid with a shear-thinning effect caused by the orientation that the particles undergo under shear [27]. This orientation in layers is more easily flow passed by the water and other layers. This cause the decrease of viscosity measured in the area $\mathrm{C}$.

\section{Area D}

In the first part of the decreasing shear rate curve, the behaviour is again shear thinning. Considerations are similar to the previous description for area C.

\section{Area $E$}

In this area the shear rate velocity does not allow the preservation of the high shear structure. The high shear structure brakes down and a formation of a new low shear structure/reorganization is present. The high shear structure seems present until the drop in viscosity measured around $8 \mathrm{~s}^{-1}$, where the curve suggests the end of the high shear structure and the reorganization in a different low shear organization. The time dependent study at $10 \mathrm{~s}^{-1}$ shows a clear time dependency.

\section{Area F}

Transition area between the low shear structure and the no shear-yield stress value.

Looking again at Figs. 1, 2, 3, 4, 5, 6 and 7 again, it is possible to find support for our hypothesis. Specifically, an additional support can be seen in Fig. 4. The difference between the increasing and decreasing shear rate curves is 
reduced at higher temperature and the viscosity decrease in general terms as well. This suggests that the energy transferred to the system allows a higher mobility of MFC chains and the increased temperature inhibits network formation.

Last, it has to be stressed that due to the heterogeneous physical and chemical nature of the samples (as MFC is) the hypothesis described in this work, is possibly just one of the main mechanisms, but not the only one. As in all the real systems, the combination of many factors is the most complete explanation. However, we believe the phenomena described here is one (if not the major) contributor and that an important discovery was made in the understanding of MFC water dispersions' gel like behaviour. More research in the area is needed and we hope that this work will stimulate many colleagues into the study of this unique and fascinating behaviour.

\section{Conclusions}

An extensive study of MFC water dispersion rheology is presented, focusing on the investigations of some properties which are fundamental for the industrial application of coatings.

For the first time a flow study of MFC suspensions at high shear rates (higher than $100,000 \mathrm{~s}^{-1}$ ) was presented, and the reported data may be a valuable help for the application of MFC in Blade, Roll and all the high shear coaters of industrial interest. MFC water dispersion shows dilatant behaviour at ultra high shear rates.

This study confirms the high network forming capacity of MFC water dispersions. No authors have previously reported the shear rate-viscosity hysteresis loop and quantitatively measured this network forming capacity in dynamic flow studies. Those discoveries can help a better understanding of the MFC characteristic and a further utilization of MFC in industrial applications. A hypothesis about the formation of the hysteresis loop was presented and discussed. The hypothesis explains all the recorded data as, for instance, the curves trend with the variation of temperature.

At low shear rates $\left(0-1000 \mathrm{~s}^{-1}\right)$, no significant differences were observed between types I and II MFC water dispersions. It was confirmed that higher temperature causes lower viscosity and also that higher temperature causes a reduction of the differences between increasing and decreasing shear rate curves. It was found that higher concentration causes an increase of viscosity and that oscillatory measurements show how the closeness of the molecules helps a network creation.

Aknowledgments The authors would like to acknowledge the project Sustainbarrier and all the partners involved in that. Moreover a special mention and acknowledgement goes to Sam Keller (S.C. Canyoning Inc.), Ana Grau (D.F. University), Prof. Alexander Malkin (Russian Academy of Sciences) and Prof. John F. Brady (Department of Chemical Engineering, Caltech), recognized experts of rheology, for the proof reading of the paper.

Open Access This article is distributed under the terms of the Creative Commons Attribution Noncommercial License which permits any noncommercial use, distribution, and reproduction in any medium, provided the original author(s) and source are credited.

\section{References}

1. Alén R (2000) In: Stenius P (ed) Forest products chemistry, book 3. Fapet Oy, Helsinki, Finland, pp 58-104

2. Alén RAlén (2000) In: Stenius P (ed) Forest products chemistry, book 3. Fapet Oy, Helsinki, Finland, pp 11-57

3. Berglund L (2006) New concepts in natural fibres composites. 27th Ris $\varnothing$ international symposium on material science. Ris $\varnothing$ National Laboratory, Roskilde, Denmark

4. Malainine ME, Mahrouz M, Dufresne A (2005) Compos Sci Technol 65:1520-1526

5. Turbak AF, Snyder FW, Sandberg KR (1983) J Appl Polym Sci: Appl Polym Symp 37:815

6. Herrick FW, Casebier RL, Hamilton JK, Sandberg KR (1983) J Appl Polym Sci: Appl Polym Symp 37:797-813

7. Nakagaito AN, Yano H (2004) Appl Phys A: Mater Sci Process 78(4):547-552

8. Huang Z-M, Zhang Y-Z, Kotaki M, Ramakrishna S (2003) Compos Sci Technol 63:2223-2253

9. Ramakrishna S, Fujihara K, Teo W-E, Yong T, Ma Z, Ramaseshan R (2006) Mater Today 9:40-50

10. Bruce DM, Hobson RN, Farrent JW, Hepworth DG (2005) Compos Part A 26:1486-1493

11. López-Rubio A, Lagaron JM, Ankerfors M, Lindström T, Nordqvist D, Mattozzi A, Hedenqvist MS (2007) Carbohydr Polym 68(4):718-727

12. Oza KP, Frank SGJJ (1986) Dispersion Sci Technol 7:543-561

13. Ougiya H, Watanabe K, Morinaga Y, Yoshinaga F (1997) Biosci Biotechnol Biochem 61:1541-1545

14. Khopade AJ, Jain NK (1990) Drug Dev Ind Pharm 24(3):289-293

15. Andresen M, Johansson L-S, Tanem BS, Stenius P (2006) Cellulose 13:665-677

16. Andresen M, Stenstad P, Møretrø T, Langsrud S, Syverud K, Johansson L-S, Stenius P (2007) Biomacromolecules 8(7):2149_ 2155

17. Burger C, Hsiao BS, Chu B (2006) Annu Rev Mater Res 36:333-368

18. Syverud K, Stenius P (2009) Cellulose 16:75-85

19. Iotti M, Fabbri P, Messori M, Pilati F, Fava PJ (2009) Polym Environ 17(1):10-19

20. Coombs J, Hall K (2000) In: Non-food agro-industrial research information. CPL Publishing Services, Newbury, England, pp 57-84

21. Mangan C (1998) In: The green chemical and polymers chain. European Commission, DG12, DG6, Luxembourg, Office for Official Publications of the European Union, Brussels, Belgium, pp 23-64

22. Pääkkö $M$, Ankerfors $M$, Kosonen $H$, Nykänen A, Ahola $S$, Österberg M, Ruokolainen M, Laine J, Larsson PT, Ikkala o, Lindström t (2007) Biomacromolecules 8(6):1934-1941

23. Abe K, Iwamoto S, Yano H (2007) Biomacromolecules 8: 3276-3278 
24. Lowys M-P, Desbrières J, Rinaudo M (2001) Food Hydrocolloids $15: 25-32$

25. Wågberg L (2007) In: Ek M, Gellestedt G, Henrikkson G (eds) Pulp and paper chemistry and technology: book 3, paper chemistry and technology. Fiber and Polymer Technology, KTH, Stockholm, Sweden, pp 47-72

26. Drehmer B, Back E (1995) Effect of dispersion variables on the papermaking properties of OCC. CPPA 3rd Research Forum on Recycling, CPPA, Montreal, Canada, p 141
27. Roper J (2000) In: Lehtinen E (ed) Pigment coating and surface sizing of paper. Fapet Oy, Helsinki, Finland, pp 635-674

28. Bertola V, Bertrand F, Tabuteau H, Bonn D, Coussot P (2003) J Rheol 47(5):1211-1226

29. Reynolds O (1885) Phil Mag 20(5):496-512

30. Hoffman RL (1972) Trans Soc Rheol 16(1):155-167

31. Laun HM, Bung R, Hess S, Loose W, Hess O, Hahn K, Hadicke E, Hingmann R, Schmidt F, Lindner P (1992) J Rheol 36(4): $743-787$ 